\title{
Guyraroká, Panambizinho e Te'Yikue: Uma experiência com cinema e novas mídias
}

\author{
Nataly Guimarães Foscaches ${ }^{1}$ \\ Universidad de Salamanca \\ Antonio Hilario Aguilera Urquiza ${ }^{2}$ \\ Universidade Federal de Mato Grosso do Sul
}

Resumo: Com base em estudo etnográfico, este artigo pretende retratar os primeiros passos em favor do empoderamento dos jovens Kaiowá e Guarani das Terras Indígenas Guyraroká, Panambizinho e Te'Yikue, de MS, por meio do cinema e das novas tecnologias, bem como a finalidade e expectativas em relação ao uso destes meios. Resultados parciais mostram que o uso destas tecnologias contribui com a melhoria da autoestima do grupo e fomenta o sentido de pertencimento destes jovens a suas comunidades. Porém, a falta de incentivo impossibilita a concretização deste processo.

Palavras-chave: Kaiowá e Guarani, cinema, novas mídias, empoderamento. 


\title{
Guyraroká, Panambizinho and Te’Yikue: experimenting with filmmaking and new media
}

\begin{abstract}
Based on ethnographic research, this paper illustrates the first steps towards filmmaking and media empowerment of young Kaiowá and Guarani from the indigenous territories Guyraroká, Panambizinho and Te'Yikue, in the State of Mato Grosso do Sul, Brazil. The work also discusses the objectives and expectations of these groups with regards to the adoption of such resources. Preliminary results show that the use of filmmaking and media technologies contributes to improving the self-esteem and the sense of community belonging of young Kaiowá and Guarani. However, a lack of support and incentives is still a major barrier to the realisation of their empowerment process.
\end{abstract}

Keywords: Kaiowá, Guarani, filmmaking, new media, empowerment.

\section{Guyraroká, Panambizinho y Te’Yikue: una experiencia con el cine y las TICs}

Resumen: Este artículo, a partir de un estudio etnográfico previo, pretende retratar los primeros pasos a favor del empoderamiento de los jóvenes Kaiowá y Guarani de las Tierras Indígenas, Guyraroká, Panambizinho y Te’Yikue, de MS, por medio del cine y de las Nuevas Tecnologías, así como la finalidad y expectativas en relación al uso de estos medios. Los resultados muestran que el uso de estas tecnologías contribuyen con la mejora de autoestima del grupo y fomenta el sentido de pertenencia a sus comunidades. Sin embargo, la falta de incentivo imposibilita la concretización del proceso.

Palabras-clave: Kaiowá y Guarani, cine, nuevas tecnologías, empoderamiento. 


\section{Primeiras aproximações}

A opção pelo tema se relaciona com os principais problemas enfrentados pelos Povos Indígenas do Brasil e de outros países latino-americanos: falta de terras, desemprego, alcoolismo, violência e suicídio. A situação atual em que se encontra estes Povos, especialmente os Kaiowá e Guarani, corresponde ao processo de recuperação dos seus territórios tradicionais, apontado como fator desencadeante da violação física e moral a qual estas sociedades são submetidas, e que ao mesmo tempo, contrasta com os interesses econômicos e políticos da elite do agrobusiness e do empresariado.

Dentro deste panorama, esta pesquisa centra-se em Mato Grosso do Sul que atualmente tem a segunda maior população indígena do país, mais de 73.00o pessoas se autodenominaram indígenas no ano de 2010, a maioria identificando-se como Kaiowá e Guarani, 51.801 indivíduos (IBGE, 2010). Contraditoriamente, este estado também se destaca em matéria de violência contra os Povos Indígenas.

Em face da violação dos direitos humanos, os Kaiowá e Guarani demostram resistência por meio de conquistas de novos espaços de relevância estratégica na busca por mais autonomia, principalmente através do ensino escolar diferenciado e do acesso à universidade. Atualmente, mais de 800 indígenas de diversas etnias cursam o ensino superior em Mato Grosso do Sul; dentre esses, 270 professores Kaiowá e Guarani de reservas indígenas e áreas de acampamentos estão matriculados na Faculdade Intercultural Indígena (Faind) da Universidade Federal da Grande Dourados (UFGD). Como consequência do empoderamento da educação ocidental, jovens indígenas Kaiowá e Guarani e Terena autodenominados como realizadores indígenas deram início ao processo de apropriação do cinema e das Novas Tecnologias.

O trabalho etnográfico apresentado neste artigo foi realizado em 2011 nas Terras Indígenas (T.I.): Guyraroká e Te’Yikue, no município de Caarapó e Panambizinho, no município de Dourados, todas em Mato Grosso do Sul, e fez parte do projeto "Cine documentário indígena: construções, reflexões e protagonismo" desenvolvido em parceria com o realizador terena, designer e representante da Associação Cultural dos Realizadores Indígenas (Ascuri), Gilmar Galache.

Tal projeto resultou na produção do documentário “Jepea'yta, a lenha principal”, o qual traz à tona a discussão sobre as experiências de aprendizagem e apropriação do cinema e das novas tecnologias pelos realizadores indígenas de Mato Grosso do Sul. As frustrações dos projetos de promoção cultural "Vídeo Índio Brasil" e "Ava Marandu - Os Guarani convidam" consistem na falta de continuidade no processo de empoderamento das ferramentas de comunicação ocidentais.

A escolha por estas Terras Indígenas Kaiowá e Guarani se justifica pelos seguintes motivos: a aldeia Te’Yikue ou T.I Caarapó, por tratar-se de uma reserva indígena considerada um exemplo para as outras comunidades devido aos exitosos projetos desenvolvidos em colaboração com o Núcleo de Estudos e Pesquisas sobre os Povos Indígenas (Neppi) da Universidade Católica Dom Bosco (UCDB); a T.I Panambizinho pelo seu histórico de resistência por meio da 
manutenção das tradições e a T.I. Guyraroká por tratar-se da realidade de um acampamento indígena.

\section{Guyraroká, Panambizinho e Te’Yikue: breve panorama histórico}

$\mathrm{Na}$ sequência vamos tratar separadamente de cada terra indígena, apresentando suas particularidades, ainda que tenham muito em comum.

\section{Guyraroká}

A denominação Guyraroká indica a importância desse território para os Kaiowá. A palavra Guyraroká pode ser traduzida como "lugar onde os seres são batizados" e também refere-se a uma metáfora religiosa sobre o local onde realizam-se as cerimônias mais importantes dentro da cultura guarani como o batismo das crianças e das plantas (Pereira, 2002:83). No passado, a T.I. Guyraroká, era considerada um centro religioso, onde ocorriam intercâmbios matrimoniais e religiosos entre grupos Kaiowá de comunidades diferentes. Até 1940 várias famílias extensas ${ }^{3}$ relacionadas entre si por relações de sociabilidade (parentesco, alianças políticas, religiosas) habitavam espaços distribuídos ao lado dos córregos Karaku e Ypyta (Pereira, 2002:3).

A expulsão dos Kaiowá de Guyraroká combina una série de fatores: a chegada de doenças desconhecidas e a violência física e simbólica exercida pelos grandes latifundiários, compradores de terra do estado (Pereira, 2002:30). Expulsos dos seus tekoha ${ }^{4}$ grande parte da população de Guyraroká mudou-se para as reservas Te'Yikue e Dourados demarcadas pelo Serviço de Proteção ao Índio (SPI). Na metade da década de 80 denominada pelos autóctones como "tempo do direito" teve início o processo de retomadas dos tekoha guasu ${ }^{5}$ pelos Kaiowá e Guarani motivados pelas mudanças na constituição e pela grave situação das reservas.

Pereira (2002:88) conta que durante a organização da retomada de Guyraroká, um dos líderes do grupo já falecido, Ambrósio Vilhalva sentiu a necessidade de aprender mais sobre o modo de vida dos xamãs, já que devido ao confinamento nas reservas os ciclos de orações foram interrompidos. Para conhecer este saber religioso Ambrósio foi até Cerro Guasu ${ }^{6}$ (Paraguai) para encontrar com os caciques mais experientes que ensinaram-lhe as instruções de como proceder durante a reocupação de Guyraroká. Posteriormente em 1990 um grupo de 30 famílias de Guyraroká que vivia confinada na reserva Te’Yikue retomou uma parcela do seu tekoha. Na sequência foram expulsos novamente, mas dessa vez permaneceram acampados à margem da rodovia.

Recentemente o Ministério da Justiça do Brasil declarou Guyraroká como posse permanente dos indígenas, no entanto a demarcação administrativa ainda deve ser realizada pelo organismo indigenista. Mesmo com o respaldo legal, as

\footnotetext{
3 Dentro do sistema social Kaiowá e Guarani, a família extensa formada pelo casal, as filhas casadas, os genros e a geração seguinte, constitui-se uma comunidade de produção, consumo e vida religiosa (Schaden 1974,25).

4 Território tradicionalmente ocupado pelos Kaiowá e Guarani. O tekoha é o lugar físico- terra, mato, águas, animais, plantas, remédios e etc- onde se realiza o teko, o modo de ser, o estado de vida kaiowá e guarani (Almeida e Mura, 2003).

5 Retomada das terras em conflito. Tekoha Guasu significa o grande território.

6 Os Kaiowá acreditam que Cerro Guasu é o centro da terra (Yvy Pyte), lugar onde Deus realizou suas feitos extraordinários no tempo dos antepassados míticos, que deram origem aos princípios que organizam a sociedade kaiowá atual (Pereira, 2002:87).
} 
ameaças de parte do setor agropecuário e das usinas de álcool a este coletivo é constante (Cavalcante, 2013:273). Frente a esta realidade, parte das famílias extensas de Guyraroká permanece acampada em parcelas de seu território e outras que vivem provisoriamente nas reservas esperam a demarcação (Pereira, 2002:34).

De acordo com o Instituto Socioambiental (ISA) a população total da T.I Guyraroká é de 841 incluindo as famílias residentes nas reservas demarcadas. No total, seriam proprietários de $\mathbf{1 1 . 5 1 3}$ hectares que ainda estão em litigio, sendo negociadas. Não obstante, estima-se que a densidade populacional de Guyraroká é muito maior. Desse total, somente 112 indígenas ocupam 50 hectares de Guyraroká que equivale a 2,23 hectares para cada família com cinco integrantes (Cavalcante, 2013:110).

Durante a realização do trabalho de campo foi possível identificar vários problemas enfrentados pela comunidade como: falta de água potável devido ao envenenamento do rio, o desgaste do solo em consequência da ocupação agropecuária, a escassez de terra para produção de alimentos de subsistência, a ausência de uma escola na comunidade, o que obriga as crianças a caminhar 35 quilômetros até o colégio mais próximo e a privação de um posto de saúde também dificulta a atenção a este coletivo.

Diante destas dificuldades e sem alternativas para sufragar suas necessidades básicas, muitos kaiowá tiveram que recorrer novamente ao trabalho nas fazendas, um exemplo é o serviço doméstico realizado pelas mulheres kaiowá (Pereira, 2002:2). Além disso, o problema mais sério é o constante clima de insegurança devido a ameaça dos capangas segundo os informantes contratados pelos fazendeiros locais. Um dos casos mais recentes de violência foi a assassinato de Ambrósio no dia o1 de dezembro de 2013. Segundo a revista Carta Capital (2013) o suposto autor do crime é um morador da própria comunidade.

\section{Panambizinho}

A princípio de 1940 a região de Mato Grosso do Sul entre o rio Brilhante e os córregos, Laranja Doce, Panambi e Hum, era um tekoha. Este tekoha estava dividido entre três aldeias indígenas: Panambi ou Lagoa Rica (Douradina/MS), Panambizinho ou Vila Cruz (Panambi na cidade de Dourados/MS) e Sucuri'y (Maracaju/MS) (Maciel,2012:39). A implantação da Colônia Nacional de Dourados afetou uma parte significativa do território Kaiowá no distrito de Panambi, especialmente Panambi e Panambizinho, que durante este período eram uma única aldeia. Esta fase esteve marcada por um intenso período de luta dos indígenas por manter e recuperar suas terras tradicionais.

A pressão da colonização culminou no processo de perda de terra pelos Kaiowá de Panambizinho o que consequentemente vem alterando a estrutura desta sociedade. Apesar disso, ao contrário do que se passou em outras T.I. durante o período de conflitos com os colonos, os rituais tradicionais continuaram a ser praticados nesta comunidade.

Os Kaiowá que resistiram à invasão de suas terras passaram a ser tratados como colonos com direito unicamente a 30 hectares por família. Além disso, a convivência entre indígenas e colonos era inviável. Os índios enquanto recebiam estes quinhões de terra eram pressionados a vender ou trocar parte do seu território com os colonos (Maciel, 2012:57). 
As famílias que conseguiram permanecer no seu território concentraramse na área posteriormente denominada T.I. Panambizinho que correspondia a dois quinhões de 30 hectares doados ao $\mathrm{Pa}^{\prime} \mathrm{i}^{7}$ Chiquito e seu filho Martim Capilé. Por este motivo, Pa'i Chiquito é considerado fundador desta T.I., onde se estabeleceu em 1920. Em 2004, depois de 50 anos de luta e resistência, os Kaiowá de Panambizinho reconquistaram mais uma parte do seu território, no total 1.272. Atualmente vivem em Panambizinho, 333 pessoas organizadas em famílias em 1.272 hectares. Os moradores contam com um posto de saúde e a Escola Municipal Indígena Pa'i Chiquito Pedro.

Embora tenham conquistado parte de seu território tradicional, os Kaiowá de Panambizinho ainda sofrem as consequências da colonização: falta de espaço para sua reprodução física e cultural, ausência de condições que favoreçam o cultivo agrícola e a escassa zona verde devido aos impactos ambientais durante a primeira metade do século XX (Maciel, 2012:89).

Por conta desses problemas, assim como em outras T.I., os homens foram obrigados a trabalhar fora de sua comunidade e trouxeram consigo novas pautas de comportamento como o consumo abusivo de álcool. A difícil situação de Panambizinho contrasta com a realidade das fazendas estabelecidas em território indígena, de um lado a aldeia devastada, por décadas de exploração intensiva (somente agora o mato começa a crescer novamente) e de outro, criações de gado, porcos, grandes plantações de arroz, milho e principalmente soja.

Frente às adversidades, os Kaiowá de Panambizinho sonham em reconquistar todo seu território e melhorar sua condição de vida. Por outra parte, os proprietários rurais, descendentes dos antigos colonos, por não compreender a totalidade dos fatos, seguem indignados com a situação e se opõem radicalmente aos interesses indígenas, pois temem perder seus territórios.

\section{Te'Yikue}

A Reserva Indígena José Bonifácio, atual T.I. Caarapó, também conhecida como aldeia Te'Yikue foi criada no dia 20 de novembro de 1924 por meio de Decreto Presidencial. Neste período o território delimitado correspondia a 3.60o hectares, entretanto, atualmente a aldeia Te'Yikue tem 3.594 hectares.

Durante os primeiros anos da reserva viviam cerca de 30 habitantes e por este motivo segundo os residentes mais antigos era possível viver de acordo com as tradições (Smaniotto, et.all. 2008:9). Com o decorrer do tempo, este número aumentou para 4.701 habitantes das etnias Kaiowá e Guarani Nandeva, a maioria procedentes de outros tekoha de Brasil e Paraguai, e atualmente já contam mais de 6.000 pessoas.

A excessiva pressão demográfica associada a apropriação de práticas agrícolas ocidentais como o uso do trator e inclusive a prática agrícola tradicional de coivara ${ }^{8}$ contribuiu com o desmatamento da zona verde da

\footnotetext{
7 Nosso pai. Entre os Kaiowá e Guarani este líder também é denominado como ñanderu o tekoaruvicha (Enciclopédia Povos Indígenas do Brasil, 2006).

8 Prática agrícola itinerante que consiste na derrubada da mata nativa, seguida pela queima da vegetação para o cultivo da terra. Terminado este processo, depois de dois ou três anos os Kaiowá e Guarani deslocavam-se para outro espaço, deixando que aquela terra se recuperasse. No passado, havia muito espaço e vegetação densa que possibilitava esta alternativa. Esse sistema evitava o esgotamento dos recursos do solo (Brand e Colman, 2010:2).
} 
reserva. Por este motivo, a caça de animais e a pesca são hoje em dia atividades impraticáveis.

Semelhante a Panambizinho, esta situação conduziu os homens ao trabalho no cultivo e colheita de cana de açúcar nas usinas de álcool. A falta da figura masculina, durante este período de ausência gerou uma série de problemas, principalmente na educação dos filhos, a instabilidade da família elementar e da família extensa. Também as mudanças nas formas de liderar dos Kaiowá e Guarani promovidas pelo SPI tiveram um impacto negativo sobre a cultura guarani. A comunidade que a princípio era liderada pelo ñanderu o tekoaruvicha, com o SPI passou a ser a figura do capitão, determinada pelo SPI, e na atualidade, passou a ter influência direta das igrejas evangélicas.

Atualmente a aldeia Te'Yikue tem acesso a estradas, escolas, posto de saúde e ao Centro de Assistência do Serviço Social (Cras). Ao lado essas instalações governamentais está a casa de reza onde são realizados os fóruns, seminários, reuniões e aulas. Dentro da reserva, destaca-se a Escola Municipal Indígena Nandejara Polo resultado de um processo de reflexão e discussão sobre educação indígena diferenciada entre líderes e educadores Kaiowá e Guarani, Prefeitura de Caarapó, Conselho Indigenista Missioneiro (Cimi) e Neppi (UCDB). Esta escola transformou-se em um espaço de reflexão entre indígenas e não-indígenas sobre os direitos constitucionais, educação escolar diferenciada, recuperação ambiental e tudo o que se refere a melhoria da qualidade de vida da comunidade (Batista, 2005:97).

\section{Projetos de apropriação das TIC e do cinema: Ponto de Cultura Teko Arandu, Vídeo Índio Brasil e Ava Marandu - Os Guarani convidam}

Antes da descrição das experiências com o uso do audiovisual e das Novas Tecnologias pelos jovens Kaiowá e Guarani é importante ressaltar alguns acontecimentos anteriores ao trabalho de campo, os quais são primordiais para compreensão do processo de empoderamento destas ferramentas não indígenas por estas sociedades.

Entre as ações financiadas pela Secretaria da Identidade e da Diversidade Cultural (SID) do Ministério da Cultura (Minc) durante o governo de Luiz Inácio Lula da Silva (2003-2011) estão os Pontos de Cultura, os projetos Vídeo Índio Brasil (VIB) e Ava Marandu- Os Guarani convidam, ações que vieram impactar diretamente os indígenas.

\section{Ponto de Cultura}

Os Pontos de cultura integram a iniciativa mais importante do Minc, o Programa Nacional de Cultura, Educação e Cidadania, Cultura Viva. Criado em 2004, o programa tem como objetivo promover o acesso aos meios de produção e difusão cultural e está dirigido a população em situação vulnerável (estudantes de escolas públicas, sociedades indígenas, campesinos, quilombolas, gays, lésbicas, transgêneros, bissexuais; agentes culturais, artistas, professores e militantes) que desenvolvem projetos de combate a exclusão social e cultural (Reis, 2013:91).

O programa Cultura Viva favorece a promoção da descentralização das políticas culturais em termos territoriais e temáticos. Por meio dos Pontos de 
Cultura, o Minc começou a atender regiões do Brasil que antes não eram beneficiadas pela instituição (Reis, 2013:91). É importante destacar que o Programa Cultura Viva no dia 23 de julho de 2014 converteu-se em uma política de Estado. Segundo o Ministério da Cultura (2014) esta nova legislação garante a longevidade e recursos para o fomento de novos Ponto de Cultura. A atual meta do Plano Nacional de Cultura é estabelecer 15 mil Pontos de Cultura até 2020, distribuídos em mais de mil municípios de todo o país.

Entre os Pontos de Cultura, destacam-se os Pontos de Cultura Indígenas. Desde sua implementação, organizações indígenas e indigenistas apresentam-se aos editais-convocatórias. Entre 2005 e 2007, o Minc estabeleceu um convênio com 23 Pontos de Culturas Indígenas e em 2010, 30 pontos foram inaugurados em terras indígenas no Acre, Amazonas e Rondônia (Ministério da Cultura, 2012:104).

Vamos tratar agora do Ponto de Cultura Tekoarandu. A experiência da aldeia Te'Yikue com o Ponto de Cultura teve início com a apresentação ao editalconvocatória do programa Cultura Viva em 2005. No entanto, o projeto só começou a funcionar três anos depois em fevereiro de 2008 quando chegou o investimento do Governo Federal. Este Ponto de Cultura Indígena denominado Tekoarandu' tem como objetivo principal a recopilação, digitalização, catalogação, produção, análise e divulgação da cultura e história dos Kaiowá e Guarani em Mato Grosso do Sul a partir da criação de uma rede digital de informação e comunicação entre os pontos de cultura. Este trabalho é realizado na sala de informática da Escola Ñandejara Polo, espaço em que a comunidade tem acesso a câmaras fotográficas, equipamentos audiovisuais e internet.

\section{Vídeo Índio Brasil y Ava Marandu: “Os Guarani convidam”}

Quanto á realização do projeto Vídeo Índio Brasil, de acordo com a coordenadora do Ponto de Cultura Guaikuru e do VIB em 2009, Andréa Freire, a criação deste surgiu devido a urgência de dar visibilidade a cultura indígena brasileira, em especial a cultura indígena sul-mato-grossense, por meio da produção audiovisual em favor da inclusão social dos Povos Indígenas. $\mathrm{O}$ objetivo principal desta iniciativa foi divulgar a representação e a autorepresentação dos Povos Indígenas no cinema e na imprensa. No total foram realizadas cinco edições.

Em 2009 e 2010 foram realizadas duas oficinas de formação em cinema, orientadas a jovens autóctones e ministradas por cineastas indígenas e nãoindígenas que trabalham com temáticas relacionadas aos Povos Indígenas. Entre eles destaca-se: Gilmar ${ }^{10}$ e o diretor da Escuela de Cine y Artes y Audiovisuales de La Paz (Bolívia) e cineasta quéchua, Iván Molina. Posteriormente, ambos realizadores converteram-se em uma referência para os jovens integrantes da Ascuri. No total foram realizadas 144 horas de curso. $\mathrm{O}$ plano de estudos incluía temas como enquadramento, elaboração de roteiro, produção, edição, montagem, fotografia, som, roteiro, capacitação de recursos e elaboração de projetos audiovisuais.

A edição do VIB em 2010 teve destaque também por exibir pela primeira vez em MS o filme polêmico "Terra Vermelha” com direção do ítalo-chileno, Marcos Bechis, protagonizada por indígenas das T.I. Guyraroká e

9 Modo sábio de viver

${ }^{10}$ Designer, realizador terena e representante da Ascuri. Foi o principal interlocutor durante o trabalho de campo. 
Panambizinho. A produção retrata o conflito entre um grupo Kaiowá e Guarani e um fazendeiro enquanto sua esposa agencia grupos de turistas interessados na flora, fauna da região e nos índios nativos.

Embora o evento tenha tido uma boa repercussão, especialmente com a sociedade não-indígena, a edição de 2011 limitou-se a exibir os filmes produzidos pelos participantes nas edições anteriores e do Ava Marandu. Em 2014, o evento foi realizado no cinema Cine Cultura de Brasília onde foram exibidos filmes sobre a temática indígena de forma mais geral.

Quanto ao Ava Marandu "Os Guarani convidam" foi um projeto cultural que consistia em uma série de atividades com enfoque nos direitos humanos dos Povos Guarani. Esta ação teve início no dia 01 de janeiro e terminou no dia 30 de janeiro de 2010 e contou com 15 mil participantes diretos e 60 mil participantes indiretos.

O objetivo do projeto foi sensibilizar a população em geral para as graves violações dos direitos humanos que afligem o povo Guarani e Kaiowá de Mato Grosso do Sul, além de promover a reflexão sobre o confinamento social e cultural ao qual estão submetidos estes grupos étnicos por meio da valorização cultural a partir de ações orientadas ao fortalecimento da autoestima principalmente dos jovens autóctones.

Esta iniciativa incluía a realização de oficinas de cinema e fotografia nas TI, concursos sobre cultura e direitos humanos, publicação da Cartilha sobre a Declaração das Nações Unidas sobre os Direitos dos Povos Indígenas, ações culturais nas escolas, mostras, exposições, manifestações e shows de artistas em prol da cultura e dos direitos do Povo Guarani.

Foram realizadas 12 oficinas de cinema e fotografia nas terras indígenas de MS durante o período de fevereiro a abril de 2010. Os líderes indígenas que participam da Aty Guasu ${ }^{11}$ foram os responsáveis pela seleção das T.I que foram contempladas pelo projeto.

Ao total, sete aldeias foram beneficiadas: Guyraroká, Te’Yikue (Caarapó/MS), Panambizinho, Jaguapiru (Dourados/MS), Yvy Katu (Japorã/MS), Amambai (Amambai/MS) y Jaguapire (Tacuru/MS). Posteriormente, os nove vídeos e as fotos produzidas pelos jovens Kaiowá e Guarani durante o curso foram apresentadas na feira cultural realizada no dia 15 de maio do mesmo ano.

\section{Críticas aos projetos}

Ainda que o Vídeo Índio Brasil tenha sido prolongado, as oficinas de formação em cinema e fotografia para jovens indígenas não tiveram continuidade. Outra crítica ao projeto foram os discursos genéricos no âmbito do evento, ou seja, não foram reconhecidas as especificidades étnicas das sociedades indígenas representadas.

Com relação ao Ava Marandu, devido a sua curta duração (6 meses) considera-se que os objetivos do projeto não foram cumpridos, tendo em vista que a finalidade desta iniciativa relacionava-se com as consequências do uso de uma ideologia colonial pela sociedade não-índia. Mais do que uma ação teria

\footnotetext{
11 Aty Guasu significa A Grande Reunião. Até 1980, esta reunião política caracterizava-se por sua localidade, mas posteriormente começou a reunir líderes Kaiowá e Guarani de distintas T.I de MS. A partir deste momento, surge o movimento Aty Guasu que entre suas funções também está a organização de reuniões articulando diversas áreas. Não obstante, as reuniões são independentes do movimento. Atualmente o movimento Aty Guasu também se utiliza das redes sociais, como o Facebook e blog.
} 
como foco importante, o surgimento de iniciativas que permitissem uma reflexão profunda e contínua sobre as relações de poder que dão suporte às atrocidades cometidas contra os Povos Indígenas do Brasil, em particular os Kaiowá e Guarani.

Questionada sobre a previsão de uma continuidade do projeto Ava Marandu, Freire, explicou que o contexto político vigente ${ }^{12}$ não favorecia mais a realização deste tipo de iniciativa, uma vez que a maioria dos partidos que ocupam o poder político atualmente são defensores do setor rural como por exemplo, o Partido do Movimento Democrático Brasileiro (PMDB) com maior representatividade no Congresso Nacional, o qual luta pela liberação de terras indígenas e quilombolas, a alteração da legislação da terra para facilitar a compra por estrangeiros e a negociação das dívidas dos representantes do agrobusiness.

Quanto ao Ponto de Cultura, embora trata-se de uma proposta distinta ao VIB e ao Ava Marandu também demonstra problemas de acessibilidade e formação. A sala de informática, por exemplo, onde realiza-se o projeto embora esteja aberta para toda a população da reserva, ficou limitada ao uso dos estudantes e professores.

A falta de cursos de formação em comunicação pelos professores e jovens participantes desta iniciativa refletiu-se no momento de construir as informações divulgadas no site do Ponto de Cultura. De acordo com o coordenador não-índio responsável pelo projeto e professor, Neimar Machado, houve situações em que os próprios indígenas reproduziram notícias produzidas pelos meios defensores do setor rural no site do projeto. Ou seja, não houve um filtro e senso crítico na leitura e divulgação das notícias.

\section{Experiências com cinema e Novas Tecnologias em Terras Indígenas}

Este é o ponto central do texto, em que tratamos da forma como os indígenas fizeram a experiência de aprendizagem destas novas tecnologias de comunicação, na tentativa de se apropriarem desta linguagem, para consumo interno e, sobretudo, para favorecer a disseminação de outras narrativas sobre a realidade indígena no estado de Mato Grosso do Sul, região fortemente marcada pelo agrobusiness.

\section{Perfil dos jovens realizadores Kaiowá e Guarani}

Os jovens escolhidos para participar dos projetos mencionados e que hoje estão envolvidos com o processo de empoderamento das novas mídias e do cinema foram escolhidos pelos líderes de suas respectivas comunidades, por este motivo é importante ter claro que estes realizadores representam determinadas famílias extensas, ou seja, famílias com prestígio dentro das Terras Indígenas. Isso porque o confinamentos destes grupos étnicos em pequenas extensões territoriais conduziu ao monopólio dos recursos por

${ }^{12}$ Esta entrevista foi concedida em 2014 durante o Governo Presidencial de Dilma Roussef do Partido dos Trabalhadores (PT) (2011-vigente), o governo de André Puccinelli do Partido do Movimento Democrático (PMDB) no estado de Mato Grosso do Sul (2007-2014) e o Governo do Pastor evangélico Gilmar Olarte do Partido Progressista (PP) na capital de MS, Campo Grande (2014-vigente). 
algumas famílias que participam dos espaços de poder e que mantêm um contato direto com as instituições não-indígenas.

Outra característica que deve-se tomar em conta é o protagonismo dos professores e estudantes nas T.I. Panambizinho e T.I. Te'Yikue dentro do movimento audiovisual indígena. Este perfil justifica-se pela importância conferida à escola indígena pelas sociedades autóctones e não-índias, pois é por meio destes espaços que os projetos são realizados nas comunidades. Além disso, devido ao empoderamento da educação ocidental pelos Kaiowá e Guarani estas instituições se converteram em um espaço de reflexão sobre o uso dos recursos audiovisuais e de novos meios por suas respectivas comunidades.

Também chama atenção a identificação dos realizadores Kaiowá e Guarani com a cultura hip hop. Especialmente na T.I Guyraroká é possível observar a presença do guaxiré $e^{13}$ intercalado com as rimas de rap e uso de roupas mais largas e bonés pelos jovens realizadores. Embora este coletivo reforce a importância das tradições, a apropriação desses elementos não-índios gera muitas controvérsias com os setores mais conversadores das comunidades, principalmente os mais velhos.

\section{Os primeiros passos em prol do empoderamento dos jovens Kaiowá e Guarani}

A maioria dos jovens da aldeia Guyraroká deu início a sua trajetória no mundo audiovisual durante o projeto Vídeo Índio Brasil e posteriormente no Ava Marandu- Os guarani convidam. Entre os filmes produzidos e destacados pelos jovens de Guyraroká estão: Ipuné Kopenoty Terenoe, Guerreiro Guarani, Chamiri Jhega, Kagui, Jerosy Pukú- cerimonia do milho branco, kunumy pepy- furação do lábio e Kaiowá Kunhatai- mulher kaiowá. É importante destacar que todos os filmes foram produzidos por grupos de até 12 pessoas durante os cursos de formação em cinema. Por este motivo não é possível atribuir o direito de autoria individual sobre as obras produzidas, pois são de caráter coletivo.

Já em Panambizinho a experiência que despertou o interesse deste coletivo, especialmente de José, 22 anos, João ${ }^{14}, 18$ anos, foi a participação no filme "Terra Vermelha". Ambos realizadores foram descobertos pela equipe "RAI cinema" (produtora italiana de Terra Vermelha) responsável por selecionar jovens indígenas para atuar na produção. Neste período o único conhecimento que José e João tinham, era como espectador.

Devido ao êxito do filme, os realizadores viajaram à Itália, França, Alemanha e outros países para participar de eventos internacionais como o Festival de Cannes (França). No entanto, depois de vestirem-se de gala e chamar atenção para a situação dramática dos Kaiowá e Guarani de Mato Grosso do Sul, José e João voltaram a dura realidade de Panambizinho. Neste sentido, relatou José:

\footnotetext{
Estava sem dinheiro, comecei a vender minhas coisas. Você aprende e fica sem nada que nem um poste. Ai eu fui indo, chegou um ponto que você se ferra, ai eu falei: Vou pra usina. E o melhor jeito de ter dinheiro. Fiquei um mês; mas, a usina é mais difícil que nunca. Cheguei um dia e quase chorei na minha rua porque ninguém ajuda. Sorte que tinha meu primo, meus amigos que me ajudavam, me orientava, me ajudava como funcionava. Todo dia tinha morto lá na usina.
}

${ }_{13}$ Gênero de canto e dança Kaiowá e Guarani. Embora faça parte do sistema xamanístico, o guaxiré reflete um momento de jogo e relaxamento (Mota e Mezacasa, 2012:2).

${ }^{14}$ Os nomes dos sujeitos entrevistados foram substituídos por nomes fictícios, a fim de preservar suas identidades. 
Posteriormente, estes realizadores tiveram outras oportunidades para dar continuidade à experiência com o cinema por meio dos projetos Vídeo Índio Brasil e Ava Marandu, assim como o casal de realizadores: o professor Kaiowá, Pedro, 26 anos, e a estudante e representante das mulheres na Ascuri, Maria, 20 anos.

Foram produzidos em Panambizinho os filmes: Jerosy Pukú- cerimônia do milho branco, Kaiowá Kunhatai-mulher Kaiowá, Kagui, Te’Yikue Teko Mbarate Guarani Kaiowá com destaque para a produção Kunumy Pepyfuração de lábio. Maria junto a outros colegas do curso de formação em cinema oferecido pelo Ava Marandu produziu o filme Kunumy Pepy. Quando a entrevistei, a realizadora kaiowá destacou seu trabalho de pesquisa e preparação do cenário para recreação de um ritual que no passado era vedado para mulheres e que atualmente já não é realizado:

\begin{abstract}
Primeiro pesquisei com o filho do cacique, depois fiz um relatório sobre isso (kunumy pepy), depois fomos gravar. Fizemos lá na casa de Juliandro, era uma casa bem simples. Só homem faz isso, tipo uma encenação (...) A gente teve que pesquisar primeiro com os mais velhos. No começo, ele não entende porque antigamente não era assim. A gente tem que ensinar como vai ser, explicando para ele, ele entende e vai aceitando. Eles gostaram.
\end{abstract}

Diferente das experiências das outras T.Is. estudadas, na aldeia Te’Yikue as ferramentas comunicacionais ocidentais há alguns anos já fazem parte do cotidiano dos estudantes e professores da escola indígena devido a existência do projeto Teko Arandu. É importante ressaltar que a infraestrutura e a organização da reserva favorece a realização de projetos entre não-indígenas e a comunidade. Historicamente, nem sempre estas iniciativas de projetos e políticas para os índios trouxeram benefícios para estas sociedades; durante muito tempo o Governo brasileiro utilizou-se dessa estratégia para manipular os Kaiowá e Guarani a se submeterem às piores condições de vida dentro das reservas ou "chiqueiros" como são denominados estes espaços pelos autóctones.

O site do Tekoarandu e twitter são mantidos por professores e estudantes da comunidade, entre eles: o técnico Kaiowá e realizador, Ronaldo e os estagiários, Caio, 17 anos e Roberto, 18 anos. Atualmente, o trabalho destes jovens consiste em publicar notícias e atualizar a web além de auxiliar outros estudantes a utilizar as ferramentas disponíveis pelo projeto. Além de fazerem uso destas novas tecnologias, os realizadores da Te'Yikue também produziram os vídeos: Kagui, Porahéi, Te'Yikue Teko Mbarate Guarani Kaiowá, Porahéi e $\mathrm{O}$ difusor da sua cultura.

\title{
O Cinema e as novas tecnologias: novas "armas" na luta dos Kaiowá e Guarani
}

Antes da chegada dos projetos nas T.Is., a necessidade do uso das ferramentas de comunicação ocidentais para fazer valer os direitos do Povo Guarani já era destacada pelos autóctones, entre eles os habitantes de Guyraroká. Em uma das entrevistas, a Kaiowá Amélia, 21 anos, comentou que durante uma Aty Guasu foi distribuído entre os participantes um documento com o título "Diretriz sobre os direitos dos Povos Indígenas", segundo ela:

Esse papel explica tudo assim, diz que tem que ter uma câmara fotográfica, pode ser celular que tenha câmara assim, tem que ter mesmo porque se acontecer alguma coisa tem que gravar, tem que tirar foto, tem que colocar no papel que veio, tem que 
dar, mostrar como é, se foi acidente, se caiu de bêbado porque assim a pessoa tem prova de como foi, ai o pessoal (as organizações públicas) que for ajudar, poderia ajudar.

O discurso de Amélia reflete a primeira etapa do processo de apropriação do audiovisual e das Novas Tecnologias pelos Kaiowá e Guarani de Guyraroká, marcada pelas denúncias de violência física e psicológica fruto dos conflitos com os grandes proprietários de terra, que com o apoio dos meios de comunicação de massa de Mato Grosso do Sul fomentam o racismo contra a população indígena.

A imprensa, por intermédio dos meios de comunicação, constrói um discurso ideológico sobre os fatos que acontecem nas terras indígenas. Da mesma maneira, os jovens de Guyraroká pretendem denunciar a violação dos seus direitos utilizando-se das ferramentas de comunicação ocidentais: "Uma máquina fotográfica digital para registrar o que passou, o que está passando aqui. O pessoal que não sabe ainda o que é que a gente passou", explica o Kaiowá Francisco, 22 anos.

É importante destacar que devido a situação de descaso do governo brasileiro em relação aos povos indígenas, em particular nos casos de retomada de território, a própria pesquisa em Guyraroká significou uma oportunidade para dar visibilidade às suas denúncias. Enfrente a câmera, o ñanderu de 22 anos, Marcos, aproveitou a oportunidade para fazer uma acusação:

\footnotetext{
Quero falar de um pistoleiro que ameaça nós aqui, de noite, de dia. Anda de moto, passa aqui. A gente fica com medo, pois nós não temos arma. Não tem ninguém para socorrer aqui e o Ambrósio também tá machucado ${ }^{15}$ quase mataram ele aqui. A gente fica preocupado, talvez aconteça alguma tragédia.
}

Já na aldeia Te'Yikue podemos constatar que aos poucos e com mais frequência, estas ferramentas começam a ser utilizadas para denúncia da violação dos direitos indígenas. Caio relata sua primeira produção sobre uma manifestação em solidariedade a outros Kaiowá e Guarani ameaçados por nãoindígenas durante o processo de retomada de um tekoha:

\begin{abstract}
Comecei a usar (a câmera) quando teve um manifesto lá na aldeia. Um pequeno manifesto que tinha na aldeinha, estava recebendo ameaça (...) também participaram os rezadores, nós estivemos lá registrando tudo também. Estava sendo ocupado, estava (indígenas que reivindicam seu tekoha) tendo problemas $e$ tiveram que chamar este pessoal da outra aldeia para poder participar lá.
\end{abstract}

Caio chama a atenção para a estratégia de retomada dos territórios tradicionalmente ocupados pelos indígenas. Além das orações dos ñanderu que guiam as famílias kaiowá e guarani durante o processo de reocupação de seus tekoha, as sociedades kaiowá e guarani vislumbram agora o surgimento de novos atores: jovens munidos com câmeras fotográficas e filmadoras que registram todo o processo e dão voz a suas comunidades.

A partir dessa perspectiva é importante destacar o caso da retomada do Tekoha Pindo Roky. Em fevereiro de 2013, o jovem Kaiowá, residente na Reserva de Caarapó, Denilson Barbosa, 15 anos, foi assassinado com um tiro na cabeça no tekoha Pindo Rocky onde hoje está localizada a fazenda de Orlandino Gonçalvez Carneiro. O jovem e outros indígenas estavam indo pescar quando

${ }_{15}$ Quando da pesquisa de campo, o líder Ambrósio encontrava-se em processo de recuperação depois de ser agredido com um machado. O líder kaiowá se havia metido em um briga com outro habitante da aldeia. 
foram abordados por três capangas contratados pelo proprietário, quando ocorreu a agressão.

Depois do enterro de Denilson, cerca de 200 famílias acamparam no local com o objetivo de protestar contra o assassinato e retomar o território tradicional reivindicado. Durante este período foi criado o perfil no facebook denominado Tekoha Pindo Roky e a Ascuri produziu um vídeo chamando a atenção para a luta dos Kaiowá e Guarani da Te’Yikue.

Segundo explicou Ronaldo, além da produção de conteúdo informativo visual e escrito com denúncias e expressões culturais Kaiowá e Guarani, outra atividade que integra o Teko Arandu é a coleta de informações sobre os conflitos entre índios e proprietário rurais, durante o processo de retomada dos territórios de ocupação tradicional indígena. A finalidade desse trabalho é dar visibilidade a esta realidade omitida pelos grandes meios de comunicação de massa e também fortalecer o movimento indígena por meio da participação em uma rede de informação digital entre sociedades indígenas:

Nós estamos tentando melhorar, sempre buscando novas alternativas de buscar
parceria com os velhos, com jovens, com escola. Nós estamos tentando coletar mais
informações sobre os conflitos, uma realidade muito difícil que não está sendo
visualizada pela política pública. Acho que o objetivo do Ponto de Cultura é
exatamente isso, ser um ponto de intercâmbio entre aldeias.

Também é importante destacar que embora o movimento audiovisual indígena ainda não esteja totalmente estabelecido já gera temor no setor rural. De acordo com Gilmar, é comum a coação e intimidação de parte dos produtores rurais aos realizadores indígenas durante a produção de filmes que favorecem a perspectiva de suas comunidades.

Por esta razão a associação tem cautela no momento de divulgar notícias sobre questões territoriais para não expor os representantes indígenas a situações perigosas. Neste sentido, é importante ressaltar, que em Mato Grosso do Sul, 250 lideranças foram vítimas de homicídio durante os anos de 2003 a 2011, segundo dados do CIMI (Relatório Anual da violência contra os povos indígenas) e a ONG Racismo ambiental (2011). No início eram atos de violência vindos de fora para dentro das comunidades. Atualmente, tendo em vista as situações de pressão externa e violência simbólica, estas sociedades em situação de retomada de terras encontram-se cada vez mais fragmentadas em termos de organização social e política, situação geradora de altos índices de violência interna.

\section{Empoderamento audiovisual e das TIC a favor do ponto de vista indígena}

A situação de violência na qual vivem estas comunidades e as ações de denúncias que fazem, acompanham o desejo de transformar os estereótipos sobre os indígenas em uma imagem real e mais favorável, conforme explicou Ambrósio:

Vai acontecer como aconteceu lá atrás (no passado), o índio é bandido é aquilo. Toda a vida o índio sempre leva a pior parte. Acontece qualquer coisa joga nas costas do índio. Nós temos que preparar os jovens dessa forma porque os meninos e as meninas estão pensando em um futuro para ter uma história e uma vitória. 
Ana complementa a ideia do seu pai colocando ênfase na urgência em dar visibilidade ao cotidiano de sua comunidade no âmbito exterior, para o não índio:

\begin{abstract}
Quero mostrar mais a cultura, mostrar toda a aldeia, como é a reza, como é o guaxiré, como é a caça, a pesca e o mais importante para nós: quando nosso pai vai atrás de alguma coisa para gente comer quando não tem o que comer. Ele vai no mato e caça para nós comer com mandioca ou farinha.
\end{abstract}

É interessante observar como esta indígena busca ressaltar os valores da sua cultura, relatando como exemplo práticas tradicionais, de caça e pesca para a sobrevivência. Nesta mesma linha, Ronaldo, da aldeia Te'Yikue, enquanto apresentava o site do Teko Arandu comentou que o elemento inovador do projeto é o uso da web para valorizar a cultura indígena dentro e fora de sua comunidade:

\begin{abstract}
Nós temos um site que é o teko arandu e objetivo desse site seria exatamente trabalhar com esta sociedade para fora, para conhecer melhor os Povos Indígenas e ver como é a realidade, as coisas que a aldeia oferece. As pessoas acessam a galeria de imagem, galeria de vídeo, as redes sociais também, twitter. Estas redes também trabalham com os Guarani e Kaiowá, o pessoal do nordeste, do norte.
\end{abstract}

Para o professor Kaiowá e realizador, Paulo, o processo de empoderamento das novas tecnologias e audiovisual pelos Povos Indígenas deve consistir em um processo que tenha como objetivo mudar as relações entre indígenas e sociedade não indígenas a partir do fortalecimento cultural e da autonomia das comunidades:

\begin{abstract}
Nós precisamos construir um olhar desde dentro da comunidade, da luta, toda questão indígena. Por exemplo, a questão da terra, da cultura, da língua, crença, realidade, as dificuldades e expressar isso de dentro para fora para que toda a sociedade perceba que o que a mídia fala sobre o índio não é bem assim. A formação não se resume em conhecer somente a tecnologia. Devemos compreender o conceito de mídia de forma geral e expressar através dela os nossos conhecimentos, a nossa lógica de pensar, para que a sociedade compreenda que não é só negativa a nossa realidade, existe coisa positiva (...).
\end{abstract}

Nesta fala o professor Paulo deixa patente o que se pretende, ao se apropriarem das novas tecnologias de audiovisual: mostrar os valores da história e cultura indígena.

\title{
Protagonismo jovem por meio do empoderamento do vídeo e das TIC
}

Uma das formas mais recorrentes de aquisição de conhecimento indígena tradicional se dá por meio da transmissão de saberes de geração em geração através da oralidade. Porém, a falta de estabilidade da estrutura social kaiowá e guarani, a tensão permanente entre indígenas e não indígenas e determinadas características demográficas dificultam este processo de aprendizagem, que chamamos de "pedagogia indígena”.

De acordo com o Censo realizado pelo Instituto Brasileiro de Geografia e Estadística (IBGE) em 2010, os indígenas que vivem em zonas rurais e terras indígenas na região centro-oeste são predominantemente jovens, em 93,6\% das terras indígenas do Brasil, a população até 24 anos ultrapassava os 50\%.

Esta grande parte da população Kaiowá e Guarani enfrenta muitos problemas os quais minam sua perspectiva de vida: os altos índices de suicídios, 
obstáculos a promoção de sua identidade étnica, falta de valorização de sua cultura, conflitos interculturais, dificuldade de acesso a saúde, educação e geração de renda. Todos estes fatores somados à fragmentação de suas respectivas famílias acabam gerando sofrimento mental que muitas vezes resulta no consumo compulsivo de drogas lícitas e ilícitas.

Cabe destacar que a maioria dos jovens Kaiowá e Guarani nasceu fora de seus lares (seus tekoha) e vive atualmente nas reservas ou sobrevive em acampamentos nas margens das estradas ou no fundo das fazendas. A falta de seu território ancestral impede que as comunidades vivenciem suas principais expressões culturais: os bailes, mitos, canções, orações e por este motivo o trabalho dos transmissores culturais (anciãos) de conectar a juventude com o tekoyma ${ }^{16}$ é a cada dia mais difícil.

Frente a diminuição da população mais velha torna-se fundamental a busca por novas alternativas dirigidas a manutenção das tradições. Diante deste quadro, os realizadores indígenas consideram o uso das novas tecnologias e do vídeo uma forma de promover e registrar os saberes kaiowá e guarani, conforme expressa Maria: “Aqui na aldeia sempre acontece alguma coisa, alguma dança ou guaxiré. Ai a gente tem que relatar isso, mostrar para outra pessoa que não vê, mostrar para a criança que não entende estas coisas. É como uma memória”.

As entrevistas com os jovens realizadores nos leva a constar que o processo de empoderamento do cinema e das novas mídias está associado a valorização, reconstrução, transmissão e reflexão das experiências do passado por meio da produção de conteúdo informativo. Esta ideia reflete-se no discurso de José:

Tem muito artesanato que está calado aqui, artesanato, a dança e a molecada se interessa, mas está tudo calado (...). Meu sonho é o que eu aprendi, o meu conhecimento (sobre cinema) passar para aquele que esta aprendendo ainda. Você vai aprender tudo e morrer sem ensinar ninguém?

Com base nestas experiências, os realizadores que hoje integram a Ascuri têm como objetivo principal fortalecer a identidade étnica da juventude indígena a partir da sabedoria elaborada por seus antepassados, resgatando vínculos desfeitos pela desapropriação de seus territórios tradicionais e a tensão entre tradição e modernidade. Trata-se da busca por reconhecer o lugar do jovem tanto na sociedade indígena como na não indígena, conforme o modo de ser Kaiowá e Guarani.

\section{Considerações finais}

Percebe-se que os resultados das formações em cinema orientadas aos jovens Kaiowá e Guarani geraram uma mobilização importante porque permitiram que estes grupos étnicos que vivem uma situação vulnerável tivessem a oportunidade de vislumbrar alternativas de participação dentro de suas comunidades e reconhecimento fora delas. Por outro lado, estas propostas produziram expectativas inviáveis, já que estas iniciativas tiveram um curto período de duração e não garantiram uma continuidade na formação, organização, capacitação e aperfeiçoamento.

Esta constatação indica que embora o Vídeo Índio Brasil e o Ava Marandu tenham fomentado a apropriação do audiovisual pela juventude Kaiowá e Guarani, estas propostas não foram pensadas como um processo de uso

${ }^{16}$ Modo de ser dos antepassados. 
consciente, necessário e político. Neste sentido difere-se o Ponto de Cultura Teko Arandu, pois, trata-se de uma proposta de reflexão crítica e contínua sobre o uso destas tecnologias ocidentais na T.I. Te'Yikue.

O estudo etnográfico nas Terras Indígenas permite concluir que o domínio técnico dos recursos cinematográficos e das Novas Tecnologias pelos jovens Kaiowá e Guarani contribuiu positivamente com a autoestima destes grupos. Já que estes instrumentos permitiram aos realizadores comunicar sua realidade e seus interesses para com sua própria comunidade e com o entorno não indígena.

Também foi possível comprovar que o uso destas tecnologias conduz a reflexão deste coletivo sobre a sua própria cultura por meio da construção de conteúdo, principalmente audiovisual, com o apoio dos anciãos, detentores da cultura tradicional. Reforçando assim o sentimento de pertencimento do jovem a sua comunidade.

Por outro lado, ainda que uso do audiovisual e das novas mídias corresponda a uma promessa de um futuro melhor para a juventude Kaiowá e Guarani a falta de investimento em iniciativas que favoreçam o empoderamento destes meios impossibilita a sua concretização.

Referências

ALMEIDA, Ruben Ferreira Thomás de; MURA, Fabio. Guarani Ñandeva. Em:< http://pib.socioambiental.org/pt/povo/guarani-nandeva/1298 > Acesso em: 11 de maio de 2015 .

BATISTA, Teresinha Aparecida da Silva. A Luta por uma escola indígena em Te’Yikue Caarapó/MS. Dissertação de mestrado, Educação, UCDB, 2005.

BRASIL. Ministério da Cultura. Plano Setorial para Culturas Indígenas. Brasília, 2012.

BRASIL. Ministério da Cultura. Pontos de Cultura já são política de Estado. Disponível em: <http://www.cultura.gov.br < Acesso em: 23 de julho de 2014

CARTA CAPITAL. Líder de acampamento Guarani Kaiowá é assassinado. Disponível em: <http://www.cartacapital.com.br > Acesso em: 10 de maio de 2015

CAVALCANTE. Thiago Leandro Vieira. Colonialismo, território $e$ territorialidade: a luta pela terra dos Kaiowá e Guarani em Mato Grosso do Sul. Tese de doutorado, Historia, Unesp, 2013.

COLMAN, Rosa Sebastiana; BRAND, Antonio Jacó. Considerações sobre o território para os Kaiowá e Guarani. Tellus, Campo Grande, n.15, 2008, p-153174

IBGE, Censo demográfico 2010. Características gerais dos indígenas. Resultados do universo. Rio de Janeiro, 2010. 
MACIEL, Nely Aparecida. História da comunidade Kaiowá da aldeia Panambizinho (1920-2005). Dourados,UFGD,2012.

MOTA, Juliana Grasiéli; MEZACASA, Roseline. Jeroky Guasu Ongosu Ita Jeguaka- Grande Festa Cocar de Pedra. Dourados, 2012 (relatório)

PEREIRA, Levi Marques (Coord.). Relatório Circunstanciado de identificação e delimitação da Terra Indígena Guarani-Kaiowá Guyraroká. Três Lagoas, Portaria N.o83/PRES/FUNAI 31-01-2001, 2002.

RACISMO AMBIENTAL. Expedição ao território Kaiowá-Guarani Cacique Marcos Verón Tekoha Nhe'e e Ayvu Arandu. Disponível em: < http://racismoambiental.net.br/> Acesso em 1 de maio de 2015

REIS, Paula Feliz dos. Políticas de Cultura a longo prazo: estudo comparativo entre o Plano Nacional de Cultura do Brasil e da Colômbia. Tese de doutorado, Cultura e Sociedade, UFBA, 2013.

RICARDO, Beto; RICARDO, Fany (Coord.). Enciclopédia Povos Indígenas do Brasil. São Paulo, Instituto Socioambiental, 2006. Disponível em: < http://pib.socioambiental.org/pt> Acesso em: 11 de mayo de 2015

SHADEN, Egon. Aspectos Fundamentais da cultura Guarani. São Paulo, Edusp, 1974

SMANIOTTO, Celson Rubens; RAMIRES, Lidio Cavanha; SKOWRONSKI, Leandro (org.). Atlas Socioambiental Terra Indígena Te'Yikue. Campo Grande, UCDB, 2008. 